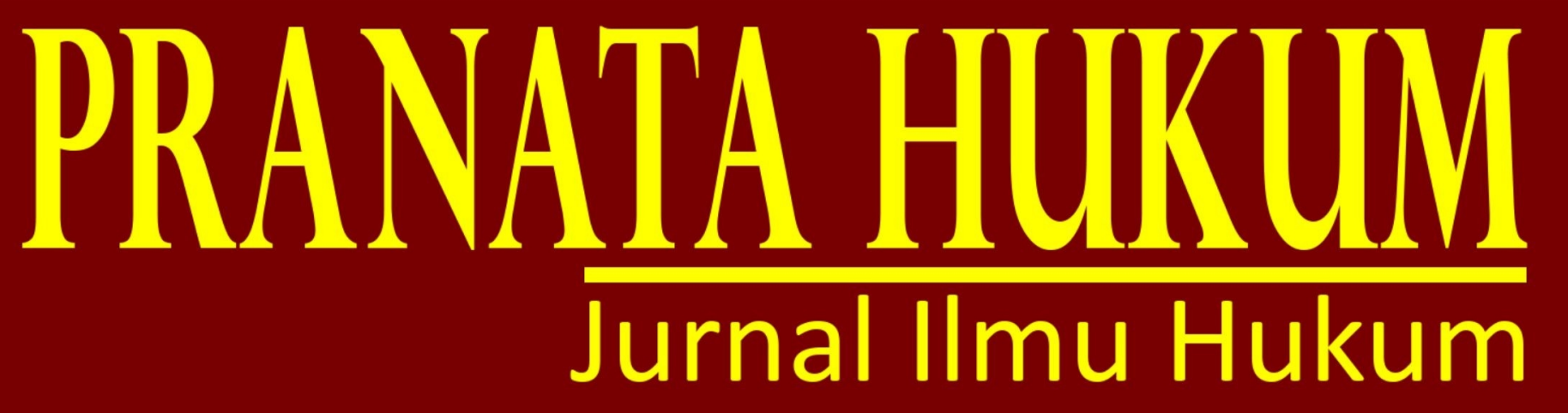

e-ISSN 2685-3213 | p-ISSN 1907-560X

EFEKTIVITAS ASEAN CONVENTION ON COUNTER TERRORISM DI DALAM MEMBERANTAS PEMBAJAKAN DI WILAYAH PERAIRAN ASIA TENGGARA

Rafi Darajati, Muhammad Syafei

PERLINDUNGAN HUKUM PENGGUNA JALAN DARI ANGKUTAN UMUM ONLINE PADA PENGGUNAAN TELEPON SAAT MENGEMUDI KENDARAAN

Rissa Afni Martinouva

ANALISIS PERTANGGUNGJAWABAN PELAKU TINDAK PIDANA MELAKUKAN PENEBANGAN POHON DALAM KAWASAN HUTAN TANPA IJIN YANG BERWENANG

Sukoco SP, Erlina B , Eddy S Wirabhumi

PERLINDUNGAN HUKUM PASIEN PADA BIDAN PRAKTIK MANDIRI DI INDONESIA PASCA DIKELUARKANNYA UNDANG-UNDANG NOMOR 4 TAHUN 2019 TENTANG KEBIDANAN Aditia Arief Firmanto

FUNGSI PENGAWASAN PERADILAN TATA USAHA NEGARA TERHADAP PERBUATAN PEMERINTAH PASCA UNDANG-UNDANG NOMOR 30 TAHUN 2014 TENTANG ADMINISTRASI PEMERINTAHAN Muhammad Rusjana

PELAKSANAAN PENGADAAN BARANG/JASA PEMERINTAH DITINJAU DARI PERPRES NOMOR 16 TAHUN 2018 TENTANG PENGADAAN BARANG/JASA PEMERINTAH DI KANTOR PERTANAHAN KOTA BANDAR LAMPUNG Aryana Wisastra, Baharudin, Indah Satria

KEWAJIBAN TANGGUNG JAWAB SOSIAL PERUSAHAAN (CORPORATE SOCIAL RESPONSIBILITY) DI INDONESIA: ANTARA LEGAL OBLIGATION ATAU MORAL OBLIGATION

Dani Amran Hakim, Dania Hellin Amrina

IMPLEMENTASI PERATURAN MENTERI AGRARIA DAN TATA RUANG/KEPALA BADAN PERTANAHAN NASIONAL NOMOR 13 TAHUN 2017 TENTANG TATA CARA BLOKIR DAN SITA PADA KANTOR PERTANAHAN KOTA BANDAR LAMPUNG

Sholin Erbin M Rajagukguk, Lintje Anna Marpaung, Herlina Ratna Sumbawa Ningrum

PEMBERIAN PATEN OBAT-OBATAN DAN PEMENUHAN HAK ASASI MANUSIA TERHADAP KESEHATAN DI INDONESIA

Chandra Muliawan

\begin{tabular}{c|c|c|c|c|}
\hline $\begin{array}{c}\text { PRANATA } \\
\text { HUKUM }\end{array}$ & $\begin{array}{c}\text { Volume } \\
14\end{array}$ & $\begin{array}{c}\text { Nomor } \\
\mathbf{2}\end{array}$ & $\begin{array}{c}\text { Halaman } \\
96-222\end{array}$ & $\begin{array}{l}\text { Bandar } \\
\text { Lampung } \\
\text { Juli 2019 }\end{array}$ \\
\hline
\end{tabular}




\section{PRANATA HUKUM}

Jurnal Ilmu Hukum

Magister Hukum

Universitas Bandar Lampung

Terbit Pertama Kali, Juli 2006

Terbit Dua Kali Setahun, Setiap Januari dan Juli

PENANGGUNG JAWAB

Rektor Universitas Bandar Lampung

KETUA PENYUNTING

Prof. Dr. Lintje Anna Marpaung, S.H., M.H

WAKIL KETUA PENYUNTING

Dr. Bambang Hartono, S.H., M.Hum

PENYUNTING PELAKSANA

Dr. Tami Rusli, S.H., M.Hum

Dr. Erlina B, S.H., M.H

Dr. Zainab Ompu Jainah, S.H., M.H

Indah Satria, S.H., M.H

Yulia Hesti, S.H., MH

\section{PENYUNTING AHLI (MITRA BESTARI)}

Prof. Dr. I Gusti Ayu Ketut Rachmi Handayani, S.H., M.M (Universitas Sebelas Maret) Prof. Dr. I Gede A.B Wiranata, S.H., M.H (Universitas Lampung) Dr. Nurhadiantomo, S.H., M.Hum (Universitas Muhammdiyah Surakarta) Dr. Erina Pane, S.H., M.H (UIN Lampung)

Alamat:

Kampus B Universitas Bandar Lampung

J1. Z.A Pagar Alam No.89 Labuhan Ratu, Bandar Lampung 35142

Telp: 0721-789825 Fax: 0721-770261

Email: jurnal.mh@ubl.ac.id 


\title{
ANALISIS PERTANGGUNGJAWABAN PELAKU TINDAK PIDANA MELAKUKAN PENEBANGAN POHON DALAM KAWASAN HUTAN TANPA IJIN YANG BERWENANG
}

\author{
Sukoco SP, ${ }^{1}$ Erlina B, ${ }^{2}$ Eddy S Wirabhumi. ${ }^{3}$
}

\begin{abstract}
The social phenomena that occurred today are still encountered cases related to the criminal acts of illegal logging in forest areas. One of the cases that have occurred is the criminal act of logging the tree in the forest area without the authorized permission. The problems in this study include: whether the cause of perpetrators to commit crimes in forest areas without authorized permits, how criminal liability against perpetrators of criminal acts Logging in forest areas without authorized permits. The results of research and settlement indicate that the cause of perpetrators to commit criminal acts of logging in forest areas without authorized permits include intrinsic factors (poor family environment, age and intelligence, and psychology of evil talent, personality), extrinsic factors (low level of education, social environment, intention and opportunity), weak religious education and ethics, lack of environmental education and forestry, lack of supervision. The advice in this research is expected to law enforcement officers with the forestry service in order to provide strict sanctions against perpetrators of criminal acts of logging in forest areas without authorized permits.
\end{abstract}

\section{Keywords: accountability, criminal offence, logging, forest area.}

\section{PENDAHULUAN}

Negara Indonesia adalah Negara hukum sebagaimana yang diatur dalam Pasal 1 ayat (3) jo Pasal 27 ayat (1) jo Pasal 28D ayat (1) Undang Undang Dasar 1945. Sebagai Negara Hukum maka Negara Indonesia menjamin segala Warga Negara sama kedudukannya di dalam hukum dan pemerintahan, serta wajib menjunjung hukum dan pemerintahan itu dengan tidak ada kecualinya. Namun dalam hukum pidana yang berlaku di Indonesia saat ini belum mampu secara maksimal mengatur dan menampung kegiatan-kegiatan dalam rangka penegakan hukum di bidang pembalakan hutan secara liar (illegal logging).

Pembalakan liar (illegal logging) merupakan kegiatan pemanfaatan hasil hutan kayu secara tidak sah yang terorganisir dan melanggar peraturan perundang-undangan, dimana pengertian terorganisir menurut Pasal 1 angka 6

\footnotetext{
${ }^{1}$ Mahasiswa Magister Hukum Universitas Bandar Lampung, sukoco.sp@gmail.com

2 Dosen Magister Hukum Universitas Bandar Lampung, erlina@ubl.ac.id

3 Dosen Magister Hukum Universitas Bandar Lampung, eddy@ubl.ac.id
} 
Undang-Undang Nomor 18 Tahun 2013 tentang Pencegahan dan Pemberantasan Perusakan Hutan yaitu kegiatan yang dilakukan oleh suatu kelompok yang terstruktur, yang terdiri atas 2 (dua) orang atau lebih, dan yang bertindak secara bersama-sama pada waktu tertentu dengan tujuan melakukan perusakan hutan, tidak termasuk kelompok masyarakat yang tinggal didalam atau disekitar kawasan hutan yang melakukan perladangan tradisional dan/atau melakukan penebangan kayu untuk keperluan sendiri dan tidak untuk tujuan komersial. Banyak ditemui kasus dimana orang/warga masyarakat bersama-sama dengan pejabat yang berwenang melakukan pembalakan liar (illegal logging) dengan alasan ekonomi didalam kawasan hutan dan perbuatan tersebut jelas dilarang dalam UndangUndang Nomor 18 Tahun 2013 tentang Pencegahan dan Pemberantasan Perusakan Hutan.

Berkaitan dengan perlindungan dari terjadinya illegal logging, UndangUndang Nomor 18 Tahun 2013 tentang Pencegahan dan Pemberantasan Perusakan Hutan mengatur dengan tegas larangan-larangan bagi setiap orang agar tidak melakukan perbuatan-perbuatan yang dapat menimbulkan kerusakan hutan. Larangan-larangan yang diatur dalam Undang-Undang Nomor 18 Tahun 2013 tentang Pencegahan dan Pemberantasan Perusakan Hutan dapat dipatuhi dan tidak dilanggar oleh setiap orang, maka Undang-Undang Nomor 18 Tahun 2013 tentang Pencegahan dan Pemberantasan Perusakan Hutan dengan tegas menentukan bahwa pelanggaran terhadap larangan yang diatur dalam UndangUndang Nomor 18 Tahun 2013 tentang Pencegahan dan Pemberantasan Perusakan Hutan merupakan tindak pidana di bidang kehutanan yang sering disebut dengan istilah illegal logging.

Dilihat dari doktrin pertanggungjawaban pidana, tindak pidana di bidang kehutanan diatur dalam Pasal 50 ayat (3) huruf e Jo Pasal 78 Ayat (5) Undang undang Nomor 41 tahun 1999 tentang kehutanan dan Pasal 12 huruf b, c Jo Pasal 82 ayat (1) huruf b, c Undang-Undang Nomor 18 Tahun 2013 tentang Pencegahan dan Pemberantasan Perusakan Hutan dan Pasal 12 huruf f Jo Pasal 84 ayat (1) Undang-Undang Nomor 18 Tahun 2013 tentang Pencegahan dan Pemberantasan Perusakan Hutan dan Pasal 104 Undang-Undang Nomor 18 Tahun 2013 tentang Pencegahan dan Pemberantasan Perusakan Hutan, dalam hal pertanggungjawaban pidana menganut doktrin mens-rea (asas kesalahan), kerena menempatkan kesengajaan sebagai unsur utama delik.

Fakta sosial yang terjadi bahwa tindak pidana illegal logging di hutan konservasi juga terjadi di Provinsi Lampung khususnya di wilayah Kabupaten Pesawaran, hal itu dapat dilihat dari Putusan Perkara Pengadilan Negeri Kalianda Nomor 559/Pid.Sus-LH/2017/PN.Kla kasus illegal logging. Dalam kasus tersebut, Terdakwa Aan Setiawan telah terbukti secara sah dan meyakinkan bersalah melakukan tindak pidana "tindak pidana melakukan penebangan pohon dalam kawasan hutan tanpa ijin yang berwenang”, sebagaimana diatur dalam Pasal 82 
ayat (1) Undang-Undang Nomor 18 Tahun 2013 tentang Pencegahan dan Pemberantasan Perusakan Hutan.

Ilegal Logging di kawasan Hutan seperti dalam Putusan Perkara Pengadilan Negeri Kalianda Nomor 559/Pid.Sus-LH/2017/PN.Kla merupakan salah satu bentuk perwujudan penegakan hukum dan penanggulangan kejahatan terhadap pelaku tindak pidana melakukan penebangan pohon dalam kawasan hutan tanpa ijin yang berwenang dalam Putusan Nomor 559/Pid.Sus-LH/2017/PN.Kla sebagaimana ketentuan Pasal 82 ayat (1) Undang-Undang Nomor 18 Tahun 2013 tentang Pencegahan dan Pemberantasan Perusakan Hutan.

Adanya kasus pembalakan liar di daerah seperti dalam Putusan Perkara Pengadilan Negeri Kalianda Nomor 559/Pid.Sus-LH/2017/PN.Kla dimana sekelompok orang karena memenuhi kebutuhan ekonominya melakukan tindakan menebang, mengambil dan membawa kayu dari dalam kawasan hutan tanpa ijin pejabat yang berwenang dikenakan tindak pidana pembalakan liar (illegal logging) bila dikaitkan dengan tujuan pemidanaan menimbulkan permasalahan yang dihubungkan dengan tujuan penanggulangan kejahatan (criminal policy) sebagai upaya perlindungan masyarakat untuk mencapai keadilan dan kesejahteraan masyarakat (social welfare), menjadikan pemikiran cukup adilkah mereka yang karena sekedar memenuhi kebutuhan ekonomi diancam dengan hukuman yang sama dengan pemilik modal yang secara jelas mencuri kayu hutan dengan tujuan untuk memperoleh keuntungan yang sebesar-besarnya.

\section{PEMBAHASAN}

\section{a. Tindak Pidana dan Penggolongan Tindak Pidana}

Tindak pidana menurut Wirjono Prodjodikuro adalah perbuatan atau serangkaian perbuatan yang padanya diletakkan sanksi pidana. Dengan demikian dilihat dari istilahnya, hanya sifat-sifat dari perbuatan saja yang meliputi suatu tindak pidana sedangkan sifat-sifat orang yang melakukan tindak pidana menjadi bagian dari persoalan lain, yaitu pertanggungjawaban pidana. Terdapat pemisahan antara pertanggungajwaban pidana dan tindak pidana, yang dikenal dengan paham dualisme, yang memisahkan antara unsur yang mengenai perbuatan dengan unsur yang melekat pada diri orangnya tentang tindak pidana. (Wirjono Prodjodikuro, 1974: 11)

Menurut Barda Nawawi Arief bahwa hukum pidana membagi tindak pidana menjadi dua sifat, (Barda Nawawi Arief, 1943: 35) yaitu:

1) delik formil, adalah delik yang dianggap telah selesai dengan dilakukannya tindakan yang dilarang dan diancam dengan hukuman oleh undang-undang.

2) delik material, adalah delik yang dianggap telah selesai dengan ditimbulkannya akibat yang dilarang dan diancam dengan hukuman oleh undang-undang.

\section{b. Pemidanaan dan Tujuan Pemidanaan}


Teori tujuan pemidanaan dan pedoman pemidanaan sebagaimana dikemukakan oleh R. Sudarto, maka dalam usaha pembaharuan hukum pidana di Indonesia, pidana merupakan salah satu masalah urgen untuk diperbaharui. Oleh sebab itu, dalam pembaharuan hukum pidana, jenis pidana dan aturan pemidanaan mengalami perombakan total yang signifikan serta mengedepankan aspek-aspek sosial kemanusiaan dan hak asasi manusia. Beberapa perkembangan mengenai pidana dan pemidanaan dalam pembaharuan hukum pidana di antaranya sebagai berikut:

(1) Teori Tujuan Pemidanaan

Tujuan pemidanaan yaitu untuk mencegah dilakukannya tindak pidana dengan menegakkan norma hukum demi pengayoman masyarakat, menyelesaikan konflik yang ditimbulkan oelh tindak pidana, memulihkan keseimbangan, mendatangkan rasa damai dalam masyarakat, memasyarakatkan terpidana dengan mengadakan pembinaan sehingga menjadi orang baik dan berguna, dan membebaskan rasa bersalah pada terpidana.

(2) Teori Pedoman Pemidanaan

Pedoman pemidanaan yang dapat dijadikan acuan bagi hakim dalam memberikan pidana. Pedoman pemidanaan itu adalah hakim harus memperhatikan kesalahan pelaku tindak pidana, motif dan tujuan melakukan tindak pidana, cara melakukan tindak pidana, sikap batin pelaku tindak pidana, riwayat hidup dan keadaan sosial ekonomi pelaku tindak pidana, sikap dan tindakan pelaku sesudah melakukan tindak pidana, pengaruh pidana terhadap masa depan pelaku tindak pidana, pandangan masyarakat terhadap tindak pidana yang dilakukan, pengaruh tindak pidana terhadap korban atau keluarga korban, apakah tindak pidana dilakukan dengan berencana (R. Sudarto, 2006: 63).

\section{c. Penegakan Hukum Pidana dan Faktor-Faktor yang Mempengaruhi Penegakan Hukum}

Menurut Barda Nawawi Arif, secara umum dilihat dari segi fungsionalisasi, pengoperasian dan penegakan sanksi pidana dalam suatu peraturan perundangundangan agar benar-benar dapat terwujud harus melalui beberapa tahap, yaitu:

(a) Tahap formulasi, yaitu tahap perumusan atau penetapan pidana oleh pembuat undang-undang (sebagai kebijakan legislatif).

(b) Tahap aplikasi, yaitu tahap pemberian pidana oleh penegak hukum (sebagai kebijakan yudikal).

(c) Tahap eksekusi, yaitu tahap pelaksanaan pidana oleh instansi yang berwenang (sebagai kebijakan eksekutif).

\section{d. Tinjauan tentang Hutan Konservasi dan Tindak Pidana Illegal Logging}


Pembalakan liar (illegal logging) terjadi karena adanya kerjasama antara masyarakat lokal berperan sebagai pelaksana di lapangan dengan para pemodal bertindak membeli kayu-kayu hasil tebangan tersebut, adakalanya pemodal tidak hanya menampung dan membeli kayu-kayu hasil tebangan namun juga mensuplai alat-alat berat kepada masyarakat untuk kebutuhan pengangkutan. Untuk mengatasi maraknya tindak pidana pembalakan liar (illegal logging) jajaran aparat penegak hukum (penyidik Polri maupun Penyidik Pegawai Negeri Sipil yang lingkup tugasnya bertanggungjawab terhadap pengurusan hutan, Kejaksaan maupun Hakim) telah mempergunakan Undang-Undang Nomor 18 Tahun 2013 tentang Pencegahan dan Pemberantasan Perusakan Hutan sebagai instrumen hukum untuk menanggulanggi tindak pidana pembalakan liar (illegal logging), meskipun secara limitatif undang-undang tersebut tidak menyebutkan adanya istilah pembalakan liar (illegal logging). Yang dimaksud dengan pembalakan liar (illegal logging) berdasarkan Pasal 1 angka 4 Undang-Undang Nomor 18 Tahun 2013 tentang Pencegahan dan Pemberantasan Perusakan Hutan adalah semua kegiatan pemanfaatan hasil hutan kayu secara tidak sah yang terorganisasi.

Pembalakan liar (illegal logging) merupakan kegiatan pemanfaatan hasil hutan kayu secara tidak sah yang terorganisir dan melanggar peraturan perundang-undangan, dimana pengertian terorganisir menurut Pasal 1 angka 6 Undang-Undang Nomor 18 Tahun 2013 tentang Pencegahan dan Pemberantasan Perusakan Hutan yaitu kegiatan yang dilakukan oleh suatu kelompok yang terstruktur, yang terdiri atas 2 (dua) orang atau lebih, dan yang bertindak secara bersama-sama pada waktu tertentu dengan tujuan melakukan perusakan hutan, tidak termasuk kelompok masyarakat yang tinggal didalam atau disekitar kawasan hutan yang melakukan perladangan tradisional dan/atau melakukan penebangan kayu untuk keperluan sendiri dan tidak untuk tujuan komersial. Banyak ditemui kasus dimana orang/warga masyarakat bersama-sama dengan pejabat yang berwenang melakukan pembalakan liar (illegal logging) dengan alasan ekonomi didalam kawasan hutan dan perbuatan tersebut jelas dilarang dalam UndangUndang Nomor 18 Tahun 2013 tentang Pencegahan dan Pemberantasan Perusakan Hutan.

Berkaitan dengan perlindungan dari terjadinya illegal logging, UndangUndang Nomor 18 Tahun 2013 tentang Pencegahan dan Pemberantasan Perusakan Hutan mengatur dengan tegas larangan-larangan bagi setiap orang agar tidak melakukan perbuatan-perbuatan yang dapat menimbulkan kerusakan hutan. Larangan-larangan yang diatur dalam Undang-Undang Nomor 18 Tahun 2013 tentang Pencegahan dan Pemberantasan Perusakan Hutan dapat dipatuhi dan tidak dilanggar oleh setiap orang, maka Undang-Undang Nomor 18 Tahun 2013 tentang Pencegahan dan Pemberantasan Perusakan Hutan dengan tegas menentukan bahwa pelanggaran terhadap larangan yang diatur dalam UndangUndang Nomor 18 Tahun 2013 tentang Pencegahan dan Pemberantasan 
Perusakan Hutan merupakan tindak pidana di bidang kehutanan yang sering disebut dengan istilah illegal logging.

Dilihat dari doktrin pertanggungjawaban pidana, tindak pidana di bidang kehutanan diatur dalam Pasal 50 ayat (3) huruf e jo Pasal 78 Ayat (5) Undang undang Nomor 41 tahun 1999 tentang kehutanan dan Pasal 12 huruf b, c jo Pasal 82 ayat (1) huruf b, c Undang-Undang Nomor 18 Tahun 2013 tentang Pencegahan dan Pemberantasan Perusakan Hutan dan Pasal 12 huruf f jo Pasal 84 ayat (1) Undang-Undang Nomor 18 Tahun 2013 tentang Pencegahan dan Pemberantasan Perusakan Hutan dan Pasal 104 Undang-Undang Nomor 18 Tahun 2013 tentang Pencegahan dan Pemberantasan Perusakan Hutan, dalam hal pertanggungjawaban pidana menganut doktrin mens-rea (asas kesalahan), kerena menempatkan kesengajaan sebagai unsur utama delik.

Tindak pidana melakukan penebangan pohon dalam kawasan hutan tanpa ijin yang berwenang dalam Putusan Nomor 559/Pid.Sus-LH/2017/PN.Kla berdasarkan Undang-Undang Nomor 18 Tahun 2013 tentang Pencegahan dan Pemberantasan Perusakan Hutan memberikan sangsi pidana cukup berat, di samping dapat dikenakan hukuman badan dan juga dikenakan pidana denda, tetapi dalam kenyataannya para pelakunya justru semakin meningkat. Hal ini disebabkan oleh faktor penjatuhan sanksi pidana tidak memberikan dampak atau deterent effect terhadap para pelakunya. Adapun ketentuan Pasal 82 UndangUndang Nomor 18 Tahun 2013 tentang Pencegahan dan Pemberantasan Perusakan Hutan sebagi berikut:

(1) Orang perseorangan yang dengan sengaja:

a. melakukan penebangan pohon dalam kawasan hutan yang tidak sesuai dengan izin pemanfaatan hutan sebagaimana dimaksud dalam Pasal 12 huruf a;

b. melakukan penebangan pohon dalam kawasan hutan tanpa memiliki izin yang dikeluarkan oleh pejabat yang berwenang sebagaimana dimaksud dalam Pasal 12 huruf b; dan/atau

c. melakukan penebangan pohon dalam kawasan hutan secara tidak sah sebagaimana dimaksud dalam Pasal 12 huruf c dipidana dengan pidana penjara paling singkat 1 (satu) tahun dan paling lama 5 (lima) tahun serta pidana denda paling sedikit Rp500.000.000,00 (lima ratus juta rupiah) dan paling banyak Rp2.500.000.000,00 (dua miliar lima ratus juta rupiah).

(2) Dalam hal tindak pidana sebagaimana dimaksud pada ayat (1) dilakukan oleh orang perseorangan yang bertempat tinggal di dalam dan/atau di sekitar kawasan hutan, pelaku dipidana dengan pidana penjara paling singkat 3 (tiga) bulan dan paling lama 2 (dua) tahun dan/atau pidana denda paling sedikit 
Rp500.000,00 (lima ratus ribu rupiah) dan paling banyak Rp500.000.000,00 (lima ratus juta rupiah).

(3) Korporasi yang:

a. melakukan penebangan pohon dalam kawasan hutan yang tidak sesuai dengan izin pemanfaatan hutan sebagaimana dimaksud dalam Pasal 12 huruf a;

b. melakukan penebangan pohon dalam kawasan hutan tanpa memiliki izin yang dikeluarkan oleh pejabat yang berwenang sebagaimana dimaksud dalam Pasal 12 huruf b; dan/atau

c. melakukan penebangan pohon dalam kawasan hutan secara tidak sah sebagaimana dimaksud dalam Pasal 12 huruf c dipidana dengan pidana penjara paling singkat 5 (lima) tahun dan paling lama 15 (lima belas) tahun serta pidana denda paling sedikit Rp5.000.000.000,00 (lima miliar rupiah) dan paling banyak Rp15.000.000.000,00 (lima belas miliar rupiah).

e. Faktor penyebab pelaku melakukan tindak pidana melakukan penebangan pohon dalam kawasan hutan tanpa ijin yang berwenang.

Faktor penyebab pelaku melakukan tindak pidana melakukan penebangan pohon dalam kawasan hutan tanpa ijin yang berwenang dalam Putusan Nomor 559/Pid.Sus-LH/2017/PN.Kla meliputi faktor intrinsik dan ekstrinsik. Faktor intrinsik meliputi: lingkungan keluarga yang kurang baik dalam membentuk pola hubungan interaksi sosial, faktor usia dan intelegensia, dan Psikologi atau kejiwaan seseorang yang dilihat dari bakat jahat, kepribadian, emosi yang kontrofersi, motivasi, dan sebagainya. Faktor ekstrinsik meliputi: faktor lingkungan pergaulan dan pekerjaan serta faktor Niat dan Kesempatan merupakan faktor tempat dan waktu yang dapat merdorong seseorang untuk melakukan kejahatan. Faktor lain penyebab terjadinya tindak pidana melakukan penebangan pohon dalam kawasan hutan tanpa ijin yang berwenang yaitu lemahnya pendidikan agama dan etika, kurangnya pendidikan lingkungan hidup dan kehutanan, tidak adanya sanksi yang keras dan tegas atas pelaku tindak pidana melakukan penebangan pohon dalam kawasan hutan tanpa ijin yang berwenang, kurangnya pengawasan terhadap perbuatan pembalakan hutan, masih terdapat celah untuk melakukan pembalakan hutan, kurangnya kontrol masyarakat, LSM, maupun pers terhadap perbuatan pembalakan hutan tersebut sehingga memudahkan pelaku melakukan penebangan pohon dalam kawasan hutan tanpa ijin yang berwenang. 


\section{f. Pertanggungjawaban pidana terhadap pelaku tindak pidana melakukan penebangan pohon dalam kawasan hutan tanpa ijin yang berwenang dalam Putusan Nomor 559/Pid.Sus-LH/2017/PN.Kla}

Pertanggungjawaban pidana terhadap pelaku tindak pidana melakukan penebangan pohon dalam kawasan hutan tanpa ijin yang berwenang dalam Putusan Nomor 559/Pid.Sus-LH/2017/PN.Kla yakni didasarkan pada kesalahan yang memenuhi unsur melawan hukum dan tidak ada alasan pemiadaan/penghapusan sifat melawan hukum atas perbuatan dilakukan. Pertanggungjawaban pidananya adalah Terdakwa Aan Setiawan telah terbukti secara sah dan meyakinkan bersalah melakukan tindak pidana "tindak pidana melakukan penebangan pohon dalam kawasan hutan tanpa ijin yang berwenang", sebagaimana diatur dalam Pasal 82 ayat (1) Undang-Undang Nomor 18 Tahun 2013 tentang Pencegahan dan Pemberantasan Perusakan Hutan. Majelis Hakim Menjatuhkan pidana terhadap terdakwa tersebut di atas oleh karena itu dengan pidana penjara selama 1 (satu) tahun 8 (delapan) bulan dan denda sebesar Rp. 500.000.000,00 (lima ratus juta rupiah) subsidair 2 (dua) bulan kurungan. Pertanggungjawaban pidana tersebut didasarkan pada adanya unsur kesengajaan oleh pelaku (dolus), yaitu pelaku mengetahui bahwa perbuatannya dilarang oleh undang-undang tetapi tetap melakukan perbuatan tersebut sehingga tidak ada alasan pembenar maupun pemaaf baginya untuk terhindar dari pemidanaan.

\section{PENUTUP}

Faktor penyebab pelaku melakukan tindak pidana melakukan penebangan pohon dalam kawasan hutan tanpa ijin yang berwenang meliputi faktor intrinsik (lingkungan keluarga yang kurang baik, usia dan intelegensia, dan Psikologi bakat jahat, kepribadian), faktor ekstrinsik (tingkat pendidikan yang rendah, lingkungan pergaulan, Niat dan Kesempatan), lemahnya pendidikan agama dan etika, kurangnya pendidikan lingkungan hidup dan kehutanan, kurangnya pengawasan.

Pertanggungjawaban pidana terhadap Pejabat dengan sengaja melakukan Pertanggungjawaban pidana terhadap pelaku tindak pidana melakukan penebangan pohon dalam kawasan hutan tanpa ijin yang berwenang dalam Putusan Nomor 559/Pid.Sus-LH/2017/PN.Kla berupa pidana dengan pemidanaan terhadap terdakwa secara sah dan meyakinkan bersalah sebagaimana diatur dalam Pasal 82 ayat (1) Undang-Undang Nomor 18 Tahun 2013 tentang Pencegahan dan Pemberantasan Perusakan Hutan, dengan vonis pidana penjara kepada Terdakwa selama 1 (satu) tahun 8 (delapan) bulan dan denda sebesar Rp.500.000.000,00 (lima ratus juta rupiah) subsidair 2 (dua) bulan kurungan.

Aparat penegak hukum bersama Dinas Kehutanan hendaknya dapat memberikan pembinaan terhadap masyarakat terkait kesadaran untuk menjaga kelestarian lingkungan hidup dan memberikan sanksi yang tegas terhadap pelaku tindak pidana penebangan pohon dalam kawasan hutan tanpa ijin yang berwenang 
serta meningkatkan pengawasan terhadap berbagai perbuatan penebangan pohon dalam kawasan hutan tanpa ijin serta sehingga dapat meminimalisir berbagai faktor terjadinya tindak pidana penebangan pohon dalam kawasan hutan tanpa ijin yang berwenang.

Aparat penegak hukum diharapkan agar lebih memaksimalkan upaya preventif melalui sosialisasi kepada masyarakat dan lebih tegas dalam memberikan sanksi pidana terhadap pelaku tindak pidana penebangan pohon dalam kawasan hutan tanpa ijin yang berwenang guna mempertanggungjawabkan perbuatan serta memberikan efek jera terhadap pelaku.

\section{DAFTAR PUSTAKA}

\section{A. Buku}

Barda Nawawi Arief, Masalah Penegakan Hukum dan Kebijakan Hukum Pidana Dalam Penanggulangan Kejahatan, Kencana, Jakarta, 1943.

R. Sudarto, Sistem Pidana dan Penidanaan Indonesia, Pradnya Paramitha, Jakarta, 2006.

Roeslan Saleh, Perbuatan Pidana dan Pertanggungjawaban Pidana, Aksara Baru, Jakarta, 1999.

Wirjono Prodjodikuro, Tindak-Tindak Pidana Tertentu Di Indonesia, Bentang Pustaka, Jakarta, 1974.

\section{B. Peraturan Perundang-undangan}

Undang-Undang Dasar Republik Indonesia Tahun 1945 Hasil Amandemen.

Undang-Undang Nomor 1 Tahun 1946 jo Undang-Undang Nomor 73 Tahun 1958 tentang Peraturan Hukum Pidana Indonesia terkodifikasi dalam Kitab UndangUndang Hukum Pidana (KUHP).

Undang-Undang Nomor 8 Tahun 1981 tentang Hukum Acara Pidana (KUHAP).

Undang-Undang Nomor 41 Tahun 1999 tentang Kehutanan.

Undang-Undang Nomor 2 Tahun 2002 tentang Kepolisian Negara RI.

Undang-Undang Nomor 16 Tahun 2004 tentang Kejaksaan RI.

Undang-Undang Nomor 48 Tahun 2009 tentang Kekuasaan Kehakiman RI.

Undang-Undang Nomor 18 Tahun 2013 tentang Pencegahan Dan Pemberantasan Perusakan Hutan.

Peraturan Pemerintah Nomor 92 Tahun 2015 tentang Pelaksanaan KUHAP.

\section{Sumber Lain}

Achmad Baihaqi. 1998, Pembinaan dan Pengembangan Bahasa, Kamus Besar Bahasa Indonesia (Kamus Besar Bahasa Indonesia), Balai Pustaka, Jakarta.

John M. Echols dan Hassan Shadily, 2003, Kamus Bahasa Inggris, An EnglishIndonesian Dictionary, PT. Gramedia, Jakarta.

M. Marwan, 2009, Law Dictionary (Complete Edition), Reality Publisher, Surabaya. 


\section{PEDOMAN PENULISAN JURNAL PRANATA HUKUM}

1. Naskah bersifat orisinil, baik berupa hasil riset atau tinjauan atas suatu permasalahan hukum yang berkembang di masyarakat (artikel lepas), dimungkinkan juga tulisan lain yang dipandang memberikan kontribusi bagi pengembangan ilmu hukum.

2. Penulisan terdiri atas beberapa bab penulisan hasil penelitian terdiri dari 3BAB,yaitu ;

BAB I. PENDAHULUAN (Latar Belakang dan Rumusan Masalah) BAB II. PEMBAHASAN (Kerangka Teori dan Analisis), dan BAB III. PENUTUP (Kesimpulan dan Saran).

3. Tulisan menggunakan bahasa indonesia maupun bahasa inggris yang memenuhi kaidah bahasa yang baik dan benar,tulisan menggunakan bahasa indonesia disertai abstrak dalam bahasa inggris (200 kata) dan Kata kunci, ketentuan ini berlaku sebaliknya.

4. Setiap kutipan harus menyebutkan sumbernya, dan ditulis pada akhir kutipan dengan memberi tanda kurung (bodynote). Sumber kutipan harus memuat nama pengaran, tahun penerbitan dan halaman .Contoh : satu penulis (Bagir Manan, 1994: 20), Dua Penulis (Jimly Asshidiqqie dan M.Ali Syafa'at, 2005: 11), Tiga atau lebih penulis menggunakan ketentuan et.al (dkk). Untuk artikel dari internet dengan susunan: nama penulis, judul tulisan digaris bawah, alamat website, waktu download/unduh.

5. Naskah harus disertai dengan daftar pustaka atau referensi ,terutama yang digunakan sebagai bahan acuan langsung. Daftar pustaka dan referensi bersifat alfabetis dengan format; nama pengarang, judul buku, nama penerbit, kota terbit, dan tahun penerbitan. Contoh: Bagir Manan, Hubungan Antara Pemerintah Pusat dan Daerah Menurut UUD 1945, Pustaka Sinar Harapan, Jakarta, 1994.

6. Panjang tulisan antara 15-25 halaman, font times new roman dengan 1,15 spasi. Dalam hal hal tertentu berlaku pengecualian panjang tulisan.

7. Naskah disertai nama lengkap penulis, alamat e-mail dan lembaga tempat berafiliasi saat ini, dan hal lain yang dianggap penting. 


\section{Jurnal PRANATA HUKUM dimaksudkan sebagai}

media komunikasi, edukasi, dan informasi ilmiah bidang ilmu hukum khususnya, dan ilmu sosial pada umumnya. Sajian dan kemasan diupayakan komunikatif melalui bahasa ilmiah.

Redaksi mengundang semua elemen masyarakat baik civitas akademika, praktisi, lembaga masyarakat, maupun perorangan yang berminat terhadap bidang hukum untuk berpartisipasi mengembangkan gagasan, wawasan, dan pengetahuan melalui tulisan untuk dimuat dalam jurnal ini.

Melalui PRANATA HUKUM diharapkan terjadi proses pembangunan dan pengembangan bidang hukum sebagai bagian penting dari rangkaian panjang proses memajukan masyarakat bangsa.

Alamat Redaksi

PRANATA HUKUM

Kampus B Universitas Bandar Lampung Jl. ZA Pagar Alam No.89 Labuhan Ratu, Bandar

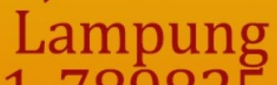

Telp: 0721-789825

Email: jurnal.mh@ubl.ac.id

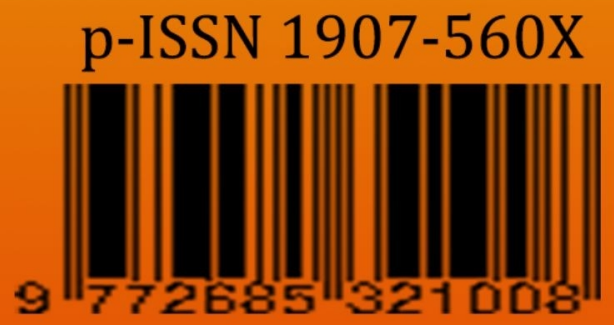

